\title{
Toll-like receptor 2 activation primes and upregulates osteoclastogenesis via lox-1
}

\author{
Kimiko Ohgi ${ }^{1}$, Hiroshi Kajiya ${ }^{2 *}$ D, Kazuko Goto-T ${ }^{3}$, Fujio Okamoto ${ }^{2}$, Yasunori Yoshinaga ${ }^{1}$, Koji Okabe ${ }^{2}$ \\ and Ryuji Sakagami ${ }^{1}$
}

\begin{abstract}
Background: Lectin-like oxidized low-density-lipoprotein receptor 1 (Lox-1) is the receptor for oxidized low-density lipoprotein (oxLDL), a mediator in dyslipidemia. Toll-like receptor (TLR)-2 and -4 are receptors of lipopolysaccharide (LPS) from Porphyromonas gingivalis, a major pathogen of chronic periodontitis. Although some reports have demonstrated that periodontitis has an adverse effect on dyslipidemia, little is clear that the mechanism is explained the effects of dyslipidemia on osteoclastogenesis. We have hypothesized that osteoclast oxLDL has directly effect on osteoclasts (OCs), and therefore alveolar bone loss on periodontitis may be increased by dyslipidemia. The present study aimed to elucidate the effect of Lox-1 on osteoclastogenesis associated with TLRs in vitro.
\end{abstract}

Methods: Mouse bone marrow cells (BMCs) were stimulated with macrophage colony-stimulating factor into bone marrow macrophages (BMMs). The cells were also stimulated with synthetic ligands for TLR2 (Pam3CSK4) or TLR4 (Lipid A), with or without receptor activator of nuclear factor kappa-B ligand (RANKL), and assessed for osteoclastogenesis by tartrate-resistant acid phosphatase (TRAP) staining, immunostaining, western blotting, flow activated cell sorting (FACS) analysis, real-time polymerase chain reaction (PCR), and reverse transcription PCR.

Results: Lox-1 expression was significantly upregulated by Pam3CSK4 and Lipid A in BMCs $(p<0.05)$, but not in BMMs. FACS analysis identified that Pam3CSK4 upregulated RANK and Lox-1 expression in BMCs. TRAP-positive cells were not increased by stimulation with Pam3CSK4 alone, but were increased by stimulation with combination combined Pam3CSK and oxLDL. Expression of both Lox-1 and myeloid differentiation factor 88 (MyD88), an essential adaptor protein in the TLR signaling pathway, were suppressed by inhibitors of TLR2, TLR4 and mitogen-activated protein kinase (MAPK).

Conclusions: This study supports that osteoclastogenesis is promoted under the coexistence of oxLDL by TLR2-induced upregulation of Lox-1 in BMCs. This indicates that periodontitis could worsen with progression of dyslipidemia.

Keywords: Dyslipidemia, Osteoclastogenesis, Toll-like receptor, Lectin-like oxidized low-density-lipoprotein receptor 1

\section{Background}

Osteoclasts (OCs) are multinucleated, bone-adhering cells, formed by fusion of mononuclear monocyte/macrophage progenitors. OCs require macrophage colony-stimulating factor (M-CSF) for proliferation and receptor activator of nuclear factor kappa-B ligand (RANKL) for fusion and maturation [1-5]. OCs act by extruding acid onto the bone surface and dissolving inorganic components within

\footnotetext{
* Correspondence: kajiya@college.fdcnet.ac.jp

${ }^{2}$ Department of Physiological Science and Molecular Biology, Fukuoka Dental College, Fukuoka 8140193, Japan

Full list of author information is available at the end of the article
}

the bone matrix [5]. Periodontitis is a chronic disease caused by bacterial infection in the gingiva [6,7], resulting in resorption of alveolar bone. It is reported that lipopolysaccharide (LPS), a major constituent of Gram-negative bacteria, can stimulate OC formation and bone resorption through activation of Toll-like receptors (TLRs) [8-10]. Porphyromonas gingivalis (P. gingivalis) is an anaerobic Gram-negative oral bacterium involved in periodontitis. LPS derived from $P$. gingivalis is different to that derived from other bacteria and acts as an agonist of both TLR4 and TLR2 [11, 12]. P. gingivalis aggravates periodontal bone resorption through differential regulation of TLR2 
and TLR4 signaling pathways in a RANKL-dependent manner [13]. Although TLR ligands have been shown to have stimulatory or inhibitory functions on osteoclastogenesis in vitro, TLR4 ligand has been shown to be a potent stimulator of bone loss in vivo [14]. It has been reported that P. gingivalis LPS stimulates periosteal OC formation due to induction of RANKL in osteoblasts by activation of TLR2 [15]. Of note, alveolar bone loss is induced by $\mathrm{P}$. gingivalis through TLR2 in mice $[13,16,17]$. Conversely, synthetic TLR2 ligand inhibits OC formation in mouse bone marrow macrophages (BMMs) stimulated with macrophage colony-stimulating factor (M-CSF) and RANKL $[18,19]$. Although RANKL induces differentiation of BMMs to OCs, simultaneous addition of LPS inhibits this process [19, 20]. However, LPS stimulation at late-stage osteoclastogenesis enhances the survival and activation of OCs [20-22]. Although $P$. gingivalis has known to promote osteoclastogenesis and bone resorption which types of TLR receptor, such as TLR2 and/or TLR4 promote bone resorption remains unclear.

Lectin-like oxidized low-density lipoprotein receptor-1 (Lox-1) was discovered as a receptor for oxidized low-density lipoprotein (oxLDL) in endothelium and vascular-rich organs [23]. Lox-1 is a multi-ligand receptor that recognizes many ligands, such as activated platelets [24], neutrophils [25], apoptotic/aged cells [26], and bacteria [27], and is expressed in many cell types [28-30]. Bone-resorbing OCs and bone-forming osteoblasts have been reported to express Lox-1, and Lox $-1^{-1-}$ mice have decreased bone mass in the steady state but are resistant to inflammatory bone destruction because of the impairment of osteoblastic RANKL expression in response to inflammation [31].

The pathology of both periodontitis and dyslipidemia involves OCs, and these lifestyle-related diseases are exacerbated by stimulation with TLRs and Lox-1, respectively. Consequently, although these disorders are reported to be associated with each other, the mechanism for this is unclear [32-34]. Some reports have shown that periodontitis increases the risk of atherosclerosis in vivo and in vitro [35-38], and that periodontitis worsens in the apolipoprotein E (ApoE)-/hyperlipidemia model [33, 35, 39]. However, there are few reports describing how dyslipidemia exacerbates periodontitis.

The purpose of this study was to clarify whether osteoclastogenesis is upregulated through Lox-1 by TLR stimulation at early- and late-stage. We showed that osteoclastogenesis was accelerated by activation of TLRs through upregulation of Lox-1 expression during bone marrow cell (BMC) differentiation into BMMs, suggesting dyslipidemia increases the risk of periodontitis.

\section{Methods}

\section{Cell culture}

All procedures were approved by the Council on Animal Care of Fukuoka Dental College (13013). Mouse BMCs were obtained from the tibia and femora of 4- to 5 -week-old ddY male mice. All mice were euthanized by cervical dislocation under anesthesia by inhalation of isoflurane at $0.5-5 \%$ with oxygen. BMCs were cultured in $\alpha$-Minimum Essential Medium ( $\alpha$-MEM; Invitrogen, Grand Island, NY, USA) containing 10\% fetal bovine serum (FBS; Biowest Nuaille, France) and antibiotics (100 U/ml penicillin $\mathrm{G}$ and $0.15 \mathrm{mg} / \mathrm{ml}$ streptomycin sulfate). After overnight culture to differentiate BMMs, non-adherent cells were cultured for 3 days with or without Pam3CSK4 (50-100 ng/ml) or lipid A (100 ng/ml) in the presence of macrophage colony-stimulating factor (M-CSF; $20 \mathrm{ng} / \mathrm{ml}$ ). For the control, phosphate-buffered saline (PBS) was administered instead of the TLR ligands. In some experiments, BMMs were used as osteoclast precursors and further cultured with RANKL $(50 \mathrm{ng} / \mathrm{ml})$ in the presence or absence of TLR ligands for 3 days. To identify OCs, cells were fixed with $3.7 \%$ formaldehyde and stained with tartrate-resistant acid phosphatase (TRAP) using the Acid Phosphatase Leukocyte Kit (Sigma-Aldrich, St. Louis, MO, USA), and defined as TRAP-positive multinucleated cells (having more than three nuclei). OCs were counted using a microscope. Each condition was tested in triplicate and all experiments were repeated at least three times.

\section{Reverse transcription (RT)-polymerase chain reaction (PCR) and real-time PCR}

Total RNA was extracted from cells using TRIzol reagent (Life Technologies Corporation, Rockville, MD, USA). First strand cDNA was synthesized using $1 \mathrm{mg}$ total RNA with Super Script II RT according to the manufacturer's instructions (Invitrogen, Grand Island, NY, USA). To detect mRNA expression of Lox- 1 and $\beta$-actin, RT-PCR was performed using the following: Lox-1 sense 5 '-AGACTGGCT CTGGCATAAAG-3', antisense 5'-AAGGCCAACATGCT TTACAT-3'; $\beta$-actin sense $5^{\prime}$-TGAGAGGGAAATCG TGCGT-3', antisense 5'-GCTGGAAGGTGGACAGTGA G-3'. PCR was performed under the following conditions: 1 min denaturation at $95^{\circ} \mathrm{C}, 1 \mathrm{~min}$ annealing at $55^{\circ} \mathrm{C}$, and 1 min extension at $72{ }^{\circ} \mathrm{C}$, using 36 cycles. PCR products were subjected to electrophoresis on $2 \%$ agarose gel and visualized with ethidium bromide. To examine the effects of MAPK inhibitors on Lox- 1 mRNA expression, BMCs in the presence of M-CSF $(20 \mathrm{ng} / \mathrm{ml})$ were cultured with or without Pam3CSK4 (100 ng/ml) or Lipid A (100 ng/ml) for 3 days after incubation with TLR2/4 inhibitor $(25 \mu \mathrm{M})$ or MAPK inhibitors, SP600125 $(5 \mu \mathrm{M})$ as c-Jun N-terminal kinase (JNK) inhibitor or U0126 $(10 \mu \mathrm{M})$ as MAP/extracellular signal-regulated kinase (ERK) kinase (MEK) inhibitor, respectively, for $1 \mathrm{~h}$. Signals of Lox-1 mRNA were 
normalized to $\beta$-actin mRNA expression levels using Image J software (NIH, Bethesda, MD, USA).

To quantify mRNA levels, cDNA samples were analyzed by quantitative real-time PCR. A total of $1 \mathrm{mg}$ of cDNA was amplified in a $20 \mu \mathrm{l}$ volume of Power SYBR Green PCR Master Mix (Applied Biosystems, Foster City, CA, USA) in a real-time PCR system (Bio-rad CFX96, Bio-rad Technologies, Inc., Santa Clara, CA, USA) and the fluorescence was monitored at each cycle. Cycle parameters were $95{ }^{\circ} \mathrm{C}$ for $30 \mathrm{~s}$ to activate Taq followed by 40 cycles of $95{ }^{\circ} \mathrm{C}$ for $5 \mathrm{~s}, 60{ }^{\circ} \mathrm{C}$ for $10 \mathrm{~s}$, and $72{ }^{\circ} \mathrm{C}$ for $40 \mathrm{~s}$. For real-time analysis, two standard curves were constructed from amplicons for both the $\beta$-actin and target gene. Target gene cDNA units in each sample were normalized to $\beta$-actin cDNA units. Finally, the relative target gene expression units were expressed as arbitrary units, calculated according to the following formula: relative target gene expression units $=$ target gene $\mathrm{cDNA}$ units $/ \beta$-actin $\mathrm{cDNA}$ units. To detect mRNA expression of Lox-1, MyD88 and glyceraldehyde 3-phosphate dehydrogenase (GAPDH), real-time PCR was performed using the following sets: Lox-1 sense 5 '-CTGCGAATGACGAGCCTGA-3', antisense 5' -TCACTGACAACACCAGGCAGAG-3'; MyD88 sense 5'-TACAGGTGGCCAGAGTGGAA-3', antisense 5'-GCAGTAGCAGATAAAGGCATCGAA-3'; GAPDH sense 5'-TGTGTCCGTCGTGGATCTGA-3', antisense 5'-TTGCTGTTGAAGTCGCAGGAG'.

\section{Immunocytochemistry}

Cells were fixed in $4 \%$ formaldehyde for $5 \mathrm{~min}$ and permeabilized with $0.05 \%$ Triton- $\times 100$ in phosphate-buffered saline (PBS) for $5 \mathrm{~min}$. Cells were incubated with goat polyclonal anti-rabbit Lox-1 antibody (1:100 dilution, ab60178, Abcam) overnight at $4{ }^{\circ} \mathrm{C}$ after blockade of nonspecific binding with $3 \%$ goat serum for $40 \mathrm{~min}$ at room temperature. Cells treated with primary antibody were washed with PBS and incubated with Alexa fluor 488-conjugated streptavidin $(2 \mu \mathrm{g} / \mathrm{ml}$, Molecular Probes, Eugene, OR) in goat anti-rabbit IgG secondary antibody (1:1500 dilution, Vector Laboratories, Burlingame, CA) for $30 \mathrm{~min}$ at room temperature. To label cell nuclei, cells were rinsed in PBS and covered with encapsulant containing 4',6-diamidino-2-phenylindole (DAPI). Fluorescence was observed using fluorescence microscopy (TMD 300, Nikon).

\section{FACS analysis}

BMCs were cultured for 3 days in $\alpha$-MEM containing $10 \%$ FBS and M-CSF with or without Pam3CSK4 (100 ng/ml) or Lipid A (100 ng/ml) for 3 days. Cells were washed twice with PBS and incubated with anti-Lox-1 and anti-RANK antibodies conjugated with phycoerythrin. The labeled cells were analyzed on a FACS using On Chip (On Chip Bio. Tec., Tokyo, Japan). The ratio of Lox-1- or RANK-positive cells among the total non-adherent BMCs was quantified using the labeled square.

\section{Western blot analysis}

Cells were lysed in Tris-NaCl-Tween (TNT) buffer containing $20 \mathrm{mM}$ tris- $\mathrm{HCl}$ (pH 7.5), $200 \mathrm{mM} \mathrm{NaCl}, 1 \%$ Triton X-100, $1 \mathrm{mM}$ dithiothreitol (DTT), and protease inhibitors (Roche, Basel, Switzerland). The protein content of the samples was measured using Pierce reagents, following the manufacturer's protocol. Protein samples $(20 \mu \mathrm{g})$ were subjected to sodium dodecyl sulfate-polyacrylamide gel electrophoresis, and proteins were then transferred to a polyvinylidene difluoride (PVDF) membrane $\left(100 \mathrm{~V}, 1 \mathrm{~h}, 4{ }^{\circ} \mathrm{C}\right)$. The membranes were incubated with anti-FDPS and anti- $\beta$-actin antibodies diluted at 1:1000 in 5\% $(w / v)$ skimmed milk solution supplemented with $0.01 \%(\mathrm{w} / \mathrm{v})$ azide overnight at $4{ }^{\circ} \mathrm{C}$. The blots were washed in Tris- buffered saline with Tween (TTBS) (10 mM tris- $\mathrm{HCl}, 50 \mathrm{mM} \mathrm{NaCl}, 0.25 \%$ Tween 20$)$ and incubated with an appropriate secondary antibody for $30 \mathrm{~min}$ at room temperature. The immunoreactive proteins were visualized using enhanced chemiluminescence reagents (GE Healthcare, Tokyo, Japan).

\section{Chemicals}

Recombinant human RANKL and M-CSF were purchased from Peprotec Co. Ltd. (Minneapolis, MN, USA). All other chemicals were obtained from Sigma-Aldrich.

\section{Data analysis}

All data are expressed as mean \pm standard error of the mean (SEM) of the number of cells (n). Statistical comparisons were performed using analysis of variance (ANOVA). A probability $(P)$ of $<0.05$ was considered significant.

\section{Results}

\section{Expression of Lox-1 was upregulated by TLR 2/4 ligands in BMCs}

To clarify the effect of TLR ligands on the expression of Lox-1 in BMCs or BMMs, cells were cultured with or without Pam3CSK4 $(100 \mathrm{ng} / \mathrm{ml})$ or Lipid A $(100 \mathrm{ng} / \mathrm{ml})$ in the presence of M-CSF for 3 days (Fig. 1a). Exposure to Pam3CSK4 or Lipid A significantly upregulated the expression of Lox-1 in BMCs $(p<0.05)$ (upper panel) but suppressed Lox-1 expression in BMMs (lower panel) compared with the control. Lox-1 mRNA expression in BMCs peaked on days 1 or 3 after incubation with Pam3CSK4 or Lipid A as assessed by real-time PCR $(p<0.05)$ (Fig. 1b, left panel). Furthermore, Lox-1 protein expression peaked on day 3 after treatment with both TLR ligands (Fig. 1b, right panel). Similar to the PCR results, protein expression of Lox-1 was also upregulated following exposure to Pam3CSK4 or Lipid A in BMCs as assessed by immunocytochemistry (Fig. 1c). 



Fig. 1 Analysis of LOX-1 in bone marrow cells (BMCs) and bone marrow macrophages (BMMs). (A, upper panel, B, C) BMCs were differentiated into BMMs with or without Pam3CSK4 (TLR2 ligand, $100 \mathrm{ng} / \mathrm{ml}$ ) or Lipid A (TLR4 ligand, $100 \mathrm{ng} / \mathrm{ml}$ ) in the presence of macrophage colony-stimulating factor (M-CSF, $20 \mathrm{ng} / \mathrm{ml})$ for 3 days. (A, lower panel) BMMs were cultured with or without Pam3CSK4 $(100 \mathrm{ng} / \mathrm{ml})$ or Lipid A (100 ng/ml) in the presence of M-CSF and receptor activator of nuclear factor kappa-B ligand (RANKL, $50 \mathrm{ng} / \mathrm{ml}$ ) for 3 days. a Polymerase chain reaction (PCR) products of LOX-1, a receptor of oxidative low density lipoprotein (oxLDL), mRNA in BMCs (upper panel) and BMMs (lower panel) were amplified using RT-PCR methods. Following stimulation with Pam3CSK4 or Lipid A, Lox-1 expression was upregulated in BMCs (upper panel) but not in BMMs (lower panel). b Lox-1 mRNA expression peaked on day 1 or 3 as determined by real-time PCR (left panel) and protein expression on day 3 (right panel). c BMCs stimulated with TLR ligands on day 3 were stained with anti-Lox-1 antibody (1:100 dilution) then incubated with Alexa fluor 488-conjugated streptavidin ( 2 $\mathrm{mg} / \mathrm{ml}$ ) in goat anti-rabbit lgG secondary antibody (1:1500 dilution). Lox-1 expression was upregulated. Data are expressed as mean \pm SEM $(n=3)$. ${ }^{*}<0.05$ compared with control

\section{TLR2/4 ligands upregulate Lox-1 and RANK in BMCs}

BMC surface expression of Lox-1 and RANK proteins was analyzed by FACS. Treatment with M-CSF slightly increased the cell surface expression of Lox-1 in BMCs in a time-dependent manner compared with untreated cells (day 0; Fig. 2, upper panel). The addition of Pam3CSK4 or Lipid A significantly upregulated the expression of Lox-1 compared with the control cells (incubated with IgG). Similar to the real-time PCR time course results, Lox-1 expression peaked at day 1 or day 3 after stimulation with Pam3CSK4 or Lipid A, respectively. In the present experiments, RANKL induced the expression of RANK, and the addition of Pam3CSK4 or Lipid A upregulated the expression of RANK in BMCs in a time-dependent manner.

\section{TLR 2/4 ligands upregulate the expression of Lox-1 in BMCs through activation of MAPK}

To assess TLR2 or 4 activation of Lox- 1 expression via the downstream pathways of TLR2/4, MyD88, and MAPKs, we examined the effects of these inhibitors on the expression of Lox-1 and RANK in BMCs using real-time PCR. Although the addition of Pam3CSK4 or Lipid A significantly increased the expression of Lox-1 and MyD88 mRNAs, TLR2 or 4 ligand-induced upregulation was reduced in the presence of TLR2/4 and MAPK inhibitor peptides, respectively (Fig. 3a), suggesting an influence towards Lox-1 expression by activation of TLR-MyD88 downstream signaling. Furthermore, the inhibitors of JNK and MEK significantly inhibited the upregulation of TLR2-induced RANK mRNAs on BMCs (Fig. 3b). These results demonstrated that TLR2/4 ligands activated Lox-1 expression through the MEK and JNK activation pathway, including MyD88.

\section{TLRs stimulation with oxLDL accelerates} osteoclastogenesis at early-phase

To clarify TLR2-induced Lox-1 upregulation on osteoclastogenesis, we examined the effect of oxLDL $(30 \mu \mathrm{g} / \mathrm{ml})$ on osteoclast differentiation on early-phase (BMC: day $0-3$ before stimulation with RANKL) and/or on late-phase (BMM: day 0-3 after RANKL stimulation) osteoclastogenesis. The number of TRAP-positive multinucleated cells were increased at early phase and decreased at late phase, 


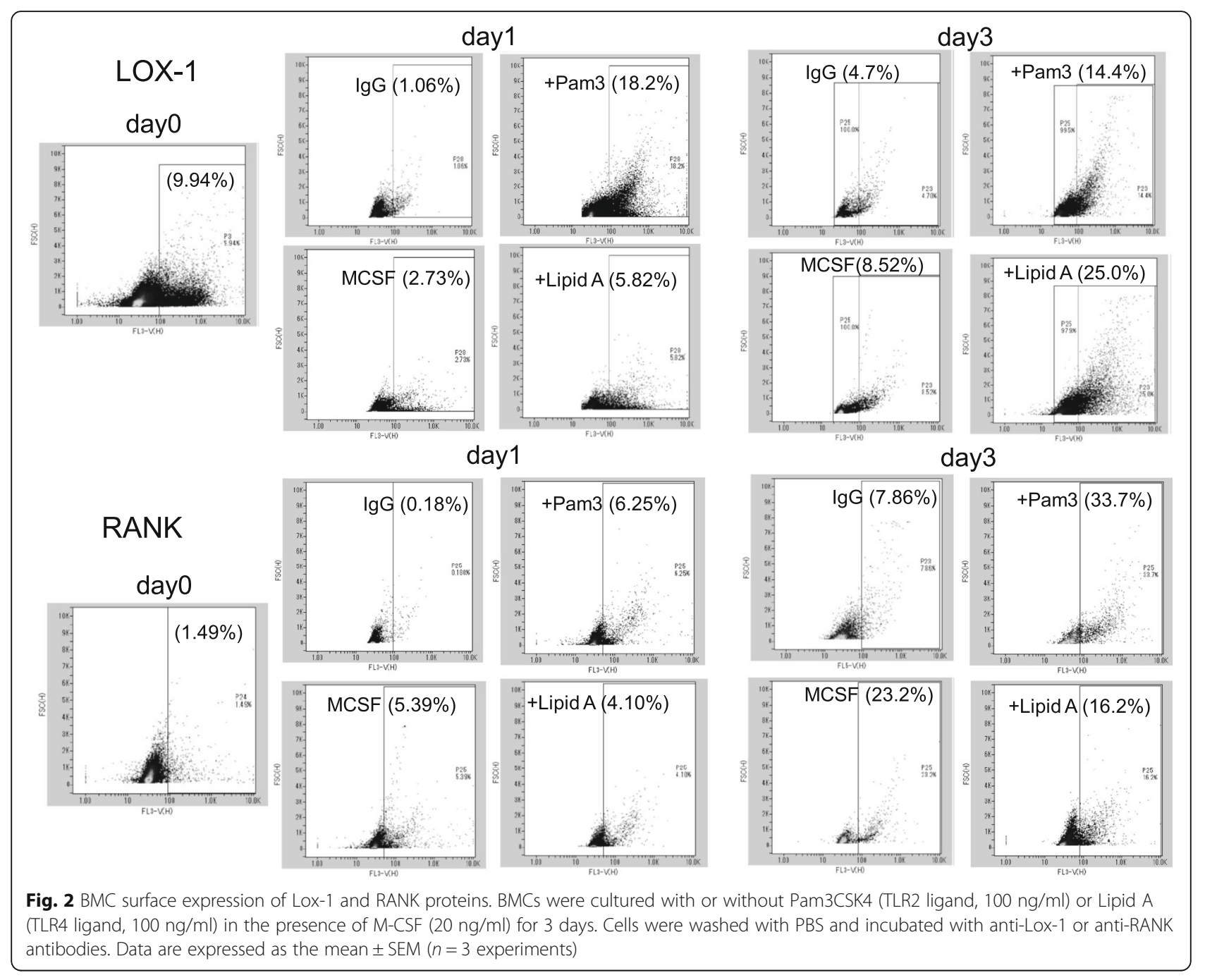

by addition of only oxLDL (Fig. 4a and b each upper panels). Furthermore, Pam3CSK4 (10 ng/ml) had no effect on early-phase, but an inhibition effect at late-phase osteoclastogenesis (Fig. $4 \mathrm{a}$ and $\mathrm{b}$ each middle panels). When we stimulated BMCs with both Pam3CSK4 $(25 \mathrm{ng} / \mathrm{ml})$ and oxLDL $(15 \mu \mathrm{g} / \mathrm{ml})$ at early-phase, numbers of TRAP-positive multinucleated cells were significantly increased (Fig. $4 \mathrm{a}$ and b each lower panels).

\section{Discussion}

P. gingivalis is known to stimulate TLR2 and/or TLR4 [11, 12] via MyD88 to modulate osteoclastogenesis [18, 40-42], resulting in alveolar bone resorption through differential regulation of TLR2 and TLR4 signaling pathways in a RANKL-dependent manner [13]. Although Lipid A, a TLR4 ligand, has been shown to be a potent stimulator of bone loss in vivo [14], little is known about whether other TLR ligands have a stimulatory or inhibitory effect on osteoclastogenesis in vitro. Furthermore, many clinical studies show that osteoporosis is associated with atherosclerosis
$[43,44]$. Although atherosclerosis is reported to result in inhibited bone formation because oxLDL blocked differentiation of osteoblast progenitor cells [45, 46], little is known about how dyslipidemia influences bone resorption. In the present study, we found that TLRs upregulated the oxLDL receptor, Lox-1, via MAPK in BMCs, resulting in promotion of osteoclastogenesis. This finding suggests that periodontitis would worsen with progression of dyslipidemia.

The subcutaneous or intraperitoneal administration of Pam3CSK4 is reported to upregulate bone resorption in vivo, suggesting that Pam3CSK4 directly promotes osteoclastogenesis from BMMs after RANKL priming [41, 47]. However, synthetic TLR2 ligand inhibits OC formation in BMMs treated with M-CSF and RANKL in vitro $[18,19]$ Furthermore, combination of RANKL and LPS inhibited osteoclastogenesis $[19,20]$. Our data also showed that numbers of TRAP-positive cells were decreased when BMMs were stimulated with Pam3CSK, compared with those treated with M-CSF and RANKL. In contrast, the 


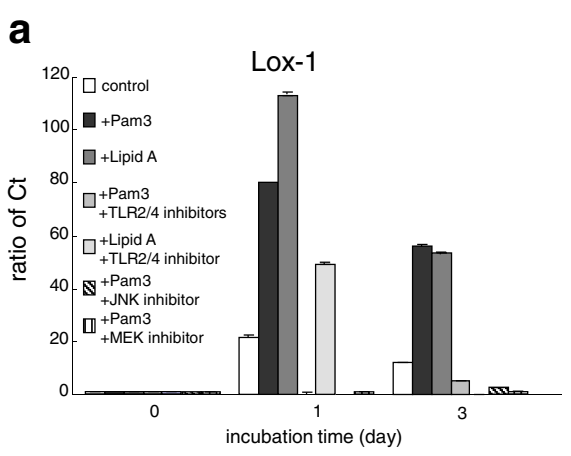

b
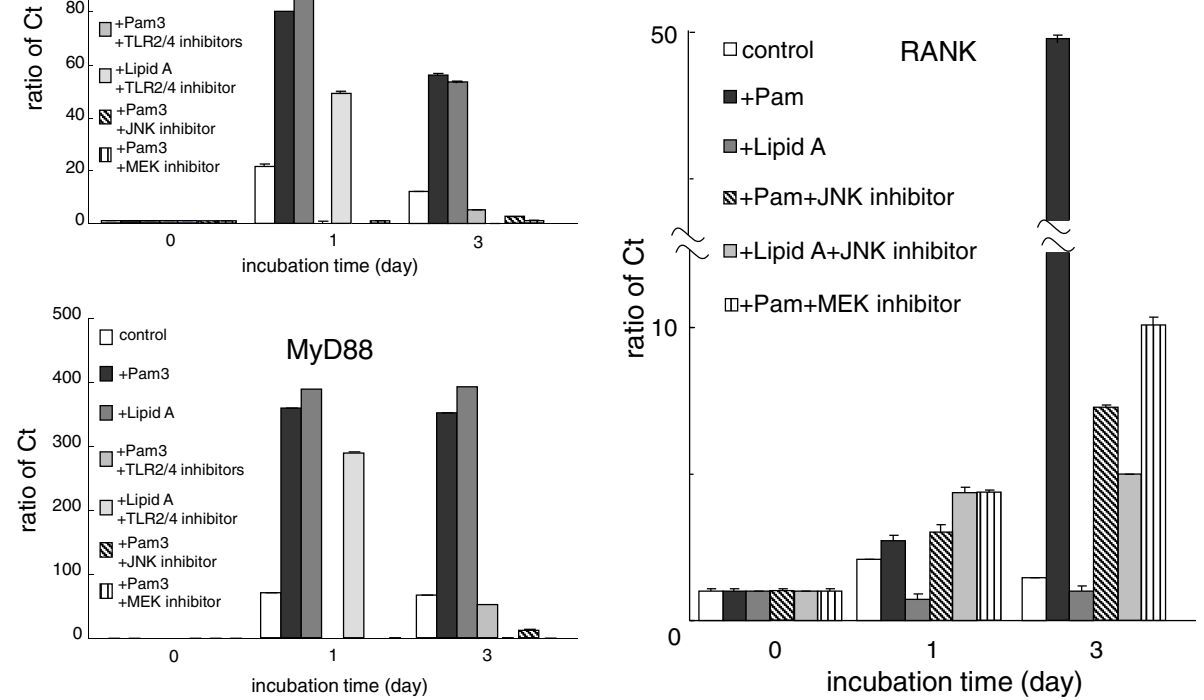

Fig. 3 Real time PCR to determine Lox-1, MyD88 and RANK expression in BMCs following addition of inhibitors. BMCs in the presence of M-CSF $(20 \mathrm{ng} / \mathrm{ml}$ ) were cultured with or without Pam3CSK4 (TLR2 ligand, $100 \mathrm{ng} / \mathrm{ml}$ ) or Lipid A (TLR4 ligand, $100 \mathrm{ng} / \mathrm{ml}$ ) for 3 days after incubation with

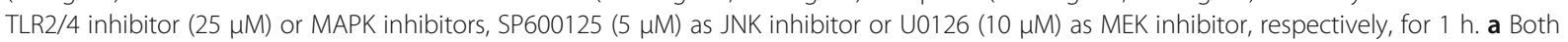
TLR2/4 inhibitor and MAPK inhibitors significantly suppressed TLR 2 or 4 ligand-induced upregulation of Lox-1 (upper panel) and MyD88 (lower panel) mRNA. b SP600125 significantly suppressed TLR 2, but not TLR 4 ligand-induced upregulation of RANK mRNA, and U0126 upregulated RANK mRNA. Data are expressed as the mean \pm SEM ( $n=3$ experiments)

addition of Pam3CSK and oxLDL, a Lox-1 ligand together at early phase, increased the number of TRAP-positive cells. Although the mechanism through which P. gingivalis-induces bone resorption via TLR2 and TLR4 is not fully understood, our results suggest that TLR-stimulation in periodontitis upregulates alveolar bone resorption under high plasma concentration of oxLDL in dyslipidemia.

OC progenitors, including BMCs and BMMs, are reported to express abundant levels of LDL receptors, such as Lox-1, in a RANKL-independent manner. Expression levels of Lox-1 are greatly decreased during osteoclastogenesis, particularly during the fusion of mononuclear cells to form multinuclear OCs [48]. The present data showed that Lox-1 expression was upregulated by TLR 2 or 4 ligands in BMCs but not in BMMs. Periodontal tissues in $\mathrm{ApoE}^{-/-}$hyperlipidemia model rats are reported to exhibit more TRAP-positive multinuclear cells and increased TLR2 and TLR4 expression levels [33], suggesting that high oxLDL concentration effects osteoclastogenesis via the elevation of TLRs. OxLDL is reported to suppress RANKL-induced osteoclastogenesis, TRAP activity, and bone-resorbing activity derived from human peripheral blood mononuclear cells in vitro. This suppression is suggested to be caused by RANKL-induced phosphorylation of ERK, p38, and JNK kinases, together with the suppression of DNA binding activities of transcriptional factors, such as nuclear factor-kappa B (NF-kappa-B) and nuclear fsctor of activated T-cells (NFAT) [49]. Our data demonstrated that TLR 2 or 4 ligand-induced Lox-1 upregulation was reduced in the presence of TLR2/4 and MAPK inhibitor, respectively, and the inhibitors of JNK and MEK significantly inhibited the upregulation of TLR 2-induced RANK mRNA on BMCs. We also found that TLR-stimulation together with oxLDL accelerated early-phase but not late-phase osteoclastogenesis, and only oxLDL stimulation suppressed RANKL-induced osteoclastogenesis, consistent with previous studies. In the present study, Pam3CSK4 was shown to upregulate the expression of RANK and Lox-1 in BMCs. Furthermore, stimulation with both Pam3CSK4 and oxLDL was shown to promote progression of osteoclastogenesis, suggesting that oxLDL-Lox-1 signaling promotes osteoclastogenesis through expression of Lox-1 by stimulating TLRs.

Similar reports have shown that plasma lipids likely play a role in maintaining bone mass $[48,50]$. A better understanding of the coupling between osteoporosis and atherosclerosis is indicated in previous studies whereby treatment of one disease may have beneficial effects on another [51-56]. The American Heart Association reported in 2012 that although periodontal interventions result in a 


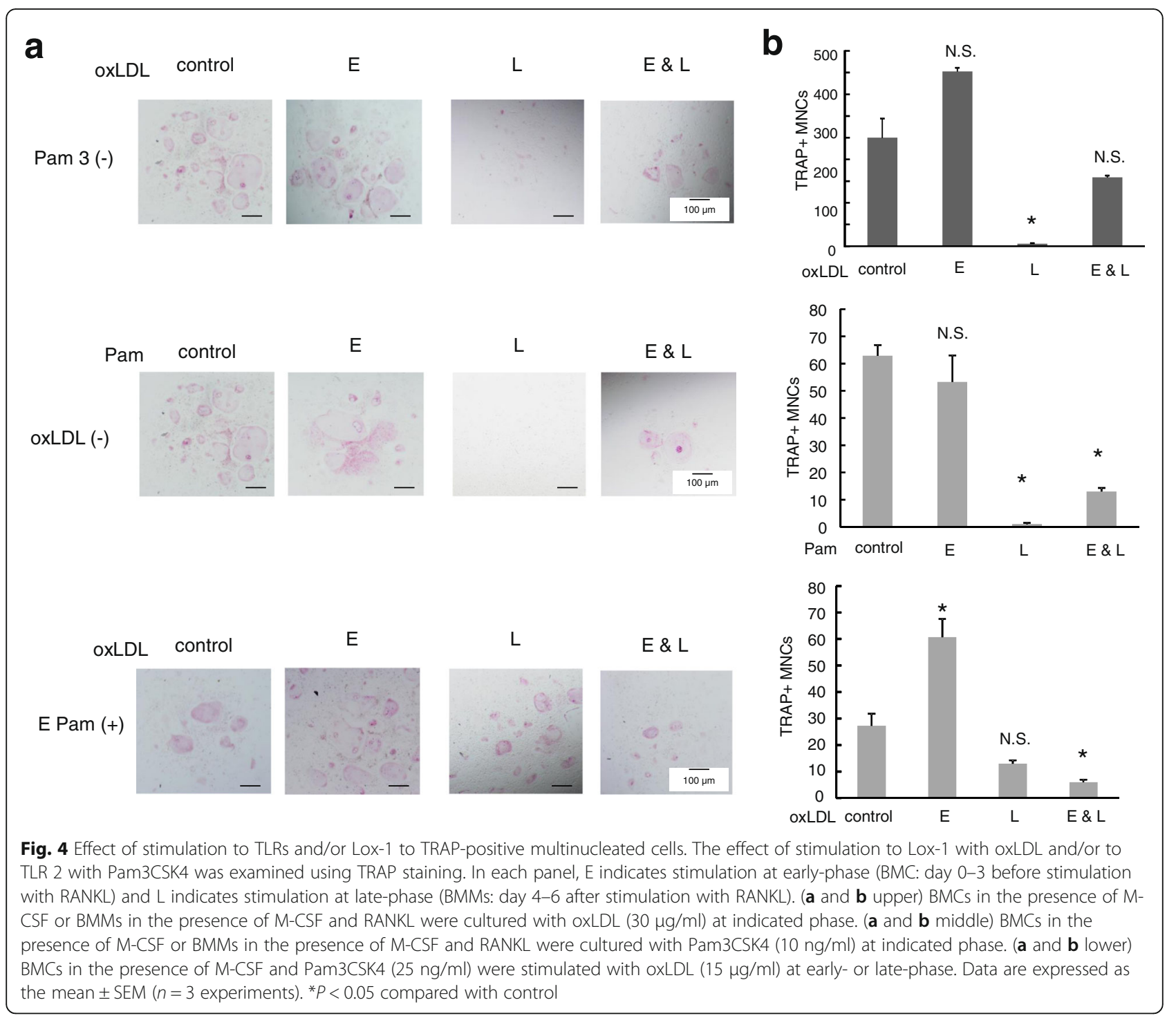

reduction in systemic inflammation and endothelial dysfunction in short-term studies, there is no evidence that they prevent atherosclerotic cardiovascular disease (ASVD) or modify its outcomes [57]. Although our data could not support that ASVD developed due to periodontitis worsening dyslipidemia, it did show that osteoclastogenesis was upregulated by TLR-stimulation, like bacterial infection, in periodontitis with dyslipidemia.

In this study, we focused on elucidating the correlation between dyslipidemia and progression of periodontitis. Our results indicated that stimulation of BMCs with TLRs, representative of a bacterial infection, upregulated Lox-1 expression resulting in promotion of osteoclastogenesis in the presence of oxLDL in dyslipidemia. Although the present data did not clarify the direct relationships between periodontitis and atherosclerotic vascular disease, periodontitis at least partially worsens by the complication of dyslipidemia.

\section{Conclusion}

In conclusion, the activation of TLR 2 and/or 4 upregulated the expression of Lox-1 through activation of MAPK in BMCs but not in osteoblasts, suggesting the promotion of osteoclastogenesis during dyslipidemia.

\section{Abbreviations}

ApoE: Apolipoprotein E; ASVD: Atherosclerotic cardiovascular disease; BMC: Bone marrow cell; BMM: Bone marrow macrophage; ERK: Extracellular signal-regulated kinase; FACS: Fluorescence activated cell sorting; JNK: c-Jun N-terminal kinase; Lox-1: Lectin-like oxidized low-density-lipoprotein receptor 1; LPS: Lipopolysaccharide; MAPK: Mitogen-activated protein kinase; M-CSF: Macrophage colony-stimulating factor; MEK: MAPK/ERK kinase; MyD88: Myeloid differentiation factor 88; NFAT: Nuclear factor of activated T-cells; NF-kappa-b: Nuclear factor-kappa B; OC: Osteoclast; oxLDL: oxidized low-density lipoprotein; P. gingivalis: Porphyromonas gingivalis; PCR: Polymerase chain reaction; RANKL: Receptor activator of nuclear factor kappa-B ligand; TLR: Toll-like receptor; TRAP: Tartrate-resistant acid phosphatase 


\section{Acknowledgements}

We thank Elizabeth Finnie, PhD, from Edanz Group (http://www.edanzediting.com/ac) for editing a draft of this manuscript.

\section{Funding}

This work was supported by a Grants-in-Aid for Scientific Research from the Ministry of Education, Culture, Sports, Science and Technology of Japan (No. 15 K11405) and Private University Research Branding Project. The authors report no conflicts of interest related to this study.

\section{Authors' contributions}

KO (Kimiko Ohgi): Conceived, designed and performed the experiments and wrote the paper; HK: Conceived, designed and performed the experiments and wrote the paper; RS: Conceived and designed the experiments; $\mathrm{KO}$ Performed the experiments; KGT: Analyzed the data; FO: Analyzed the data; YY: Analyzed the data. All authors read and approved the final manuscript.

\section{Ethics approval and consent to participate}

Not applicable.

\section{Competing interests}

The authors declare that they have no competing interests.

\section{Publisher's Note}

Springer Nature remains neutral with regard to jurisdictional claims in published maps and institutional affiliations.

\section{Author details}

${ }^{1}$ Department of Odontology, Fukuoka Dental College, Fukuoka 8140193, Japan. ${ }^{2}$ Department of Physiological Science and Molecular Biology, Fukuoka Dental College, Fukuoka 8140193, Japan. ${ }^{3}$ Department of Dental Hygiene, Fukuoka College of Health Sciences, Fukuoka 8140193, Japan.

\section{Received: 28 January 2018 Accepted: 23 May 2018}

Published online: 02 June 2018

\section{References}

1. Walsh NC, Gravallese EM. Bone remodeling in rheumatic disease: a question of balance. Immunol Rev. 2010;233(1):301-12

2. Bartold PM, Cantley MD, Haynes DR. Mechanisms and control of pathologic bone loss in periodontitis. Periodontol 2000. 2010;53:55-69.

3. Schett G, Gravallese E. Bone erosion in rheumatoid arthritis: mechanisms, diagnosis and treatment. Nat Rev Rheumatol. 2012;8(11):656-64.

4. Souza PP, Lerner UH. The role of cytokines in inflammatory bone loss. Immunol Investig. 2013;42(7):555-622

5. Lorenzo J, Horowitz M, Choi Y. Osteoimmunology: interactions of the bone and immune system. Endocr Rev. 2008;29(4):403-40.

6. Schwartz Z, Goultschin J, Dean DD, Boyan BD. Mechanisms of alveolar bone destruction in periodontitis. Periodontol 2000. 1997;14:158-72.

7. Kajiya M, Giro G, Taubman MA, Han X, Mayer MP, Kawai T. Role of periodontal pathogenic bacteria in RANKL-mediated bone destruction in periodontal disease. J Oral Microbiol. 2010;2:1-16.

8. Itoh K, Udagawa N, Kobayashi K, Suda K, Li X, Takami M, Okahashi N, Nishihara T, Takahashi N. Lipopolysaccharide promotes the survival of osteoclasts via toll-like receptor 4, but cytokine production of osteoclasts in response to lipopolysaccharide is different from that of macrophages. J Immunol. 2003;170(7):3688-95.

9. Sato N, Takahashi N, Suda K, Nakamura M, Yamaki M, Ninomiya T, Kobayashi Y, Takada H, Shibata K, Yamamoto M, Takeda K, Akira S, Noguchi T, Udagawa N. MyD88 but not TRIF is essential for osteoclastogenesis induced by lipopolysaccharide, diacyl lipopeptide, and IL-1alpha. J Exp Med. 2004;200(5):601-11.

10. Nakamura H, Fukusaki Y, Yoshimura A, Shiraishi C, Kishimoto M, Kaneko T, Hara Y. Lack of toll-like receptor 4 decreases lipopolysaccharide-induced bone resorption in $\mathrm{C} 3 \mathrm{H} / \mathrm{HeJ}$ mice in vivo. Oral Microbiol Immunol. 2008; 23(3):190-5

11. Li X, Kato N, Mezawa M, Li Z, Wang Z, Yang L, Sasaki Y, Kaneko T, Takai H, Yoshimura A, Ogata Y. Transcriptional regulation of bone sialoprotein gene by Porphyromonas gingivalis lipopolysaccharide. J Cell Biochem. 2010; 110(4):823-33.

12. Darveau RP, Pham TT, Lemley K, Reife RA, Bainbridge BW, Coats SR, Howald WN, Way SS, Hajjar AM. Porphyromonas gingivalis lipopolysaccharide contains multiple lipid a species that functionally interact with both toll-like receptors 2 and 4. Infect Immun. 2004:72(9):5041-51.

13. Lin J, Bi L, Yu X, Kawai T, Taubman MA, Shen B, Han X. Porphyromonas gingivalis exacerbates ligature-induced, RANKL-dependent alveolar bone resorption via differential regulation of toll-like receptor 2 (TLR2) and TLR4. Infect Immun. 2014;82(10):4127-34.

14. Sakuma Y, Tanaka K, Suda M, Komatsu Y, Yasoda A, Miura M, Ozasa A, Narumiya S, Sugimoto Y, Ichikawa A, Ushikubi F, Nakao K. Impaired bone resorption by lipopolysaccharide in vivo in mice deficient in the prostaglandin E receptor EP4 subtype. Infect Immun. 2000;68(12):6819-25.

15. Kassem A, Henning P, Lundberg P, Souza PP, Lindholm C, Lerner UH. Porphyromonas gingivalis stimulates bone resorption by enhancing RANKL (receptor activator of NF-kB ligand) through activation of toll-like receptor 2 in osteoblasts. J Biol Chem. 2015;290(33):20147-58.

16. Burns E, Bachrach G, Shapira L, Nussbaum G. Cutting edge: TLR2 is required for the innate response to Porphyromonas gingivalis: activation leads to bacterial persistence and TLR2 deficiency attenuates induced alveolar bone resorption. J Immuno. 2006;177(12):8296-300.

17. Papadopoulos G, Weinberg EO, Massari P, Gibson FC 3rd, Wetzler LM, Morgan EF, Genco CA, et al. Macrophage-specific TLR2 signaling mediates pathogen-induced TNF-dependent inflammatory oral bone loss. J Immunol. 2013;190(3):1148-57

18. Zhang P, Liu J, Xu Q, Harber G, Feng X, Michalek SM, Katz J. TLR2dependent modulation of osteoclastogenesis by Porphyromonas gingivalis through differential induction of NFATC1 and NF-kappaB. J Biol Chem. 2011; 286(27):24159-69.

19. Yang J, Ryu YH, Yun $\mathrm{CH}$, Han SH. Impaired osteoclastogenesis by staphylococcal lipoteichoic acid through toll-like receptor 2 with partial involvement of MyD88. J Leukoc Biol. 2009;86(4):823-31.

20. Takami M, Kim N, Rho J, Choi Y. Stimulation by toll-like receptors inhibits osteoclast differentiation. J Immunol. 2002;169(3):1516-23.

21. Zou W, Bar-Shavit Z. Dual modulation of osteoclast differentiation by lipopolysaccharide. J Bone Miner Res. 2002;17(7):1211-8.

22. Liu J, Wang S, Zhang P, Said-Al-Naief N, Michalek SM, Feng X. Molecular mechanism of the bifunctional role of lipopolysaccharide in osteoclastogenesis. J Biol Chem. 2009;284(18):12512-23.

23. Sawamura T, Kume N, Aoyama T, Moriwaki H, Hoshikawa H, Aiba Y, Tanaka T, Miwa S, Katsura Y, Kita T, Masaki T. An endothelial receptor for oxidized low-density lipoprotein. Nature. 1997;386(6620):73-7.

24. Mitra S, Goyal T, Mehta JL. Oxidized LDL, LOX-1 and atherosclerosis. Cardiovasc Drugs Ther. 2011;25(5):419-29.

25. Guzik K, Skret J, Smagur J, Bzowska M, Gajkowska B, Scott DA, Potempa JS. Cigarette smoke-exposed neutrophils die unconventionally but are rapidly phagocytosed by macrophages. Cell Death Dis. 2011;2:e131. https://doi.org/ 10.1038/cddis.2011.13

26. Oka K, Sawamura T, Kikuta K, Itokawa S, Kume N, Kita T, Masaki T. Lectin-like oxidized low-density lipoprotein receptor 1 mediates phagocytosis of aged/ apoptotic cells in endothelial cells. Proc Natl Acad Sci U S A. 1998:95(16):9535-40.

27. Shimaoka T, Kume N, Minami M, Hayashida K, Sawamura T, Kita T, Yonehara S. LOX-1 supports adhesion of gram-positive and gram-negative bacteria. J Immunol. 2001;166(8):5108-14.

28. Yoshimoto R, Fujita Y, Kakino A, Iwamoto S, Takaya T, Sawamura T. The discovery of LOX-1, its ligands and clinical significance. Cardiovasc Drugs Ther. 2011;25(5):379-91.

29. Kosaka H, Yoneyama H, Zhang L, Fujii S, Yamamoto A, Igarashi J. Induction of LOX-1 and iNOS expressions by ischemia-reperfusion of rat kidney and the opposing effect of L-arginine. FASEB J. 2003;17(6):636-43.

30. Takanabe-Mori R, Ono K, Sowa N, Wada H, Takaya T, Horie T, Satoh-Asahara N, Shimatsu A, Fujita M, Sawamura T, Hasegawa K. Lectin-like oxidized lowdensity lipoprotein receptor- 1 is required for the adipose tissue expression of proinflammatory cytokines in high-fat diet-induced obese mice. Biochem Biophys Res Commun. 2010;398(3):576-80.

31. Nakayachi M, Ito J, Hayashida C, Ohyama Y, Kakino A, Okayasu M, Sato T, Ogasawara T, Kaneda T, Suda N, Sawamura T, Hakeda Y. Lectin-like oxidized low-density lipoprotein receptor-1 abrogation causes resistance to inflammatory bone destruction in mice, despite promoting osteoclastogenesis in the steady state. Bone. 2015;75:170-82.

32. D'Aiuto F, Sabbah W, Netuveli G, Donos N, Hingorani AD, Deanfield J, Tsakos G. Association of the metabolic syndrome with severe periodontitis in a large U.S. population-based survey. J Clin Endocrinol Metab. 2008; 93(10):3989-94 
33. T T, Ekuni D, Azuma T, Irie K, Endo Y, Kasuyama K, Yoneda T, Morita M. Involvement of toll-like receptor 2 and 4 in association between dyslipidemia and osteoclast differentiation in apolipoprotein E deficient rat periodontium. Lipids Health Dis. 2013;12:1.

34. Noack B, Jachmann I, Roscher S, Sieber L, Kopprasch S, Lück C, Hanefeld M, Hoffmann T. Metabolic diseases and their possible link to risk indicators of periodontitis. J Periodontol. 2000;71(6):898-903.

35. Koizumi Y, Kurita-Ochiai T, Oguchi S, Yamamoto M. Nasal immunization with Porphyromonas gingivalis outer membrane protein decreases $P$. Gingivalis-induced atherosclerosis and inflammation in spontaneously hyperlipidemic mice. Infect Immun. 2008;76(7):2958-65.

36. Maekawa T, Takahashi N, Tabeta K, Aoki Y, Miyashita H, Miyauchi S, Miyazawa H, Nakajima T, Yamazaki K. Chronic oral infection with Porphyromonas gingivalis accelerates atheroma formation by shifting the lipid profile. PLoS One. 2011;6(5):e20240.

37. Hayashi C, Gudino CV, Gibson FC 3rd, Genco CA. Pathogen-induced inflammation at sites distant from oral infection: bacterial persistence and induction of cell-specific innate immune inflammatory pathways. Mol Oral Microbiol. 2010:25(5):305-16.

38. Velsko IM, Chukkapalli SS, Rivera MF, Lee JY, Chen H, Zheng D, Bhattacharyya I, Gangula PR, Lucas AR, Kesavalu L. Active invasion of oral and aortic tissues by Porphyromonas gingivalis in mice causally links periodontitis and atherosclerosis. PLoS One. 2014;9(5):e97811.

39. Fukasawa A, Kurita-Ochiai T, Hashizume T, Kobayashi R, Akimoto Y, Yamamoto M. Porphyromonas gingivalis accelerates atherosclerosis in C57BL/6 mice fed a high-fat diet. Immunopharmacol Immunotoxicol. 2012; 34(3):470-6.

40. Kawai T, Adachi O, Ogawa T, Takeda K, Akira S. Unresponsiveness of MyD88deficient mice to endotoxin. Immunity. 1999;11(1):115-22.

41. Mazière C, Louvet L, Gomila C, Kamel S, Massy Z, Mazière JC. Oxidized low density lipoprotein decreases Rankl-induced differentiation of osteoclasts by inhibition of Rankl signaling. J Cell Physiol. 2009;221(3):572-8.

42. Shimazu T, Villena J, Tohno M, Fujie H, Hosoya S, Shimosato T, Aso H, Suda Y, Kawai Y, Saito T, Makino S, Ikegami S, Itoh H, Kitazawa H. Immunobiotic lactobacillus jensenii elicits anti-inflammatory activity in porcine intestinal epithelial cells by modulating negative regulators of the toll-like receptor signaling pathway. Infect Immun. 2012;80(1):276-88.

43. Demer LL. Vascular calcification and osteoporosis: inflammatory responses to oxidized lipid. Int J Epidemiol. 2002;31(4):737-41.

44. Yamaguchi T, Sugimoto T, Yano S, Yamauchi M, Sowa H, Chen Q, Chihara K. Plasma lipids and osteoporosis in postmenopausal women. Endocr J. 2002; 49(2):211-7.

45. Parhami F, Tintut Y, Beamer WG, Gharavi N, Goodman W, Demer LL. Atherogenic high-fat diet reduces bone mineralization in mice. J Bone Miner Res. 2001;16(1):182-8.

46. Parhami F, Garfinkel A, Demer LL. Role of lipids in osteoporosis. Arterioscler Thromb Vasc Biol. 2000;20(11):2346-8

47. Kim J, Yang J, Park OJ, Kang SS, Kim WS, Kurokawa K, Yun CH, Kim HH, Lee $\mathrm{BL}, \mathrm{Han} \mathrm{SH}$. Lipoproteins are an important bacterial component responsible for bone destruction through the induction of osteoclast differentiation and activation. J Bone Miner Res. 2013;28(11):2381-91.

48. Okayasu M, Nakayachi M, Hayashida C, Ito J, Kaneda T, Masuhara M, Suda N, Sato T, Hakeda Y. Low-density lipoprotein receptor deficiency causes impaired osteoclastogenesis and increased bone mass in mice because of defect in osteoclastic cell-cell fusion. J Biol Chem. 2012; 287(23):19229-41.

49. Jiang Y, Lü X, Man C, Han L, Shan Y, Qu X, Liu Y, Yang S, Xue Y, Zhang Y. Lactobacillus acidophilus induces cytokine and chemokine production via NF-KB and p38 mitogen-activated protein kinase signaling pathways in intestinal epithelial cells. Clin Vaccine Immunol. 2012;19(4):603-8.

50. Parhami F, Morrow AD, Balucan J, et al. Lipid oxidation products have opposite effects on calcifying vascular cell and bone cell differentiation. A possible explanation for the paradox of arterial calcification in osteoporotic patients. Arterioscler Thromb Vasc Biol. 1997;17:680-7.

51. Mundy G, Garrett R, Harris S, Chan J, Chen D, Rossini G, Boyce B, Zhao M, Gutierrez $\mathrm{G}$. Stimulation of bone formation in vitro and in rodents by statins. Science. 1999;286(5446):1946-9.

52. Johnston CC Jr, Bjarnason NH, Cohen FJ, Shah A, Lindsay R, Mitlak BH, Huster W, Draper MW, Harper KD, Heath H 3rd, Gennari C, Christiansen C, Arnaud CD, Delmas PD. Long-term effects of raloxifene on bone mineral density, bone turnover, and serum lipid levels in early postmenopausal women: three-year data from 2 double-blind, randomized, placebocontrolled trials. Arch Intern Med. 2000;160(22):3444-50.

53. Rogers MJ. Statins: lower lipids and better bones? Nat Med. 2000;6(1):21-3.

54. Toledano JE, Partridge NC. Statins: not just for cholesterol? Trends Endocrinol Metab. 2000;11(7):255-6.

55. Ferber D. Osteoporosis. Cholesterol drugs show promise as bone builders. Science. 2000;288(5475):2297-8.

56. Ylitalo R. Bisphosphonates and atherosclerosis. Gen Pharmacol. 2000;35(6):287-96

57. Lockhart PB, Bolger AF, Papapanou PN, Osinbowale O, Trevisan M, Levison ME, Taubert KA, Newburger JW, Gornik HL, Gewitz MH, Wilson WR, Smith SC Jr, Baddour LM. American Heart Association rheumatic fever, endocarditis, and Kawasaki disease Committee of the Council on cardiovascular disease in the young, council on epidemiology and prevention, council on peripheral vascular disease, and council on clinical cardiology: periodontal disease and atherosclerotic vascular disease: does the evidence support an independent association?: a scientific statement from the American Heart Association. Circulation. 2012;125(20):2520-44.

\section{Ready to submit your research? Choose BMC and benefit from:}

- fast, convenient online submission

- thorough peer review by experienced researchers in your field

- rapid publication on acceptance

- support for research data, including large and complex data types

- gold Open Access which fosters wider collaboration and increased citations

- maximum visibility for your research: over $100 \mathrm{M}$ website views per year

At BMC, research is always in progress.

Learn more biomedcentral.com/submissions 